\title{
Management of Fistula in ANO in a Tertiary Care Hospital of Northern Andhra Pradesh
}

\author{
Rama Chandra Mohan Mallapragada ${ }^{1}$, Burra Viswa Chaitanya ${ }^{2}$ \\ ${ }^{1}$ Assistant Professor, Department of General Surgery, ${ }^{2}$ Assistant Professor, Department of General Surgery, NRI General \\ Hospital, Visakhapatnam, India
}

Corresponding author: Dr Burra Viswa Chaitanya, Assistant Professor, Department of General Surgery, NRI General Hospital, Visakhapatnam, India

DOI: http://dx.doi.org/10.21276/ijcmsr.2019.4.3.2

How to cite this article: Rama Chandra Mohan Mallapragada, Burra Viswa Chaitanya. Management of fistula in ANO in a tertiary care hospital of Northern Andhra Pradesh. International Journal of Contemporary Medicine Surgery and Radiology. 2019;4(3):C6-C10.

\section{A B S T R A C T}

Introduction: Fistula in ano is an epitheliazed tract between the anal canal and the perianal skin, most commonly due to an infection in the anal crypts and can occur after abscess drainage. Crohn's disease, trauma, radiation, or malignancy can also be a cause. The aim of this study was to provide a survey of the presentation, demography and predisposing factors of fistula-in-ano and to propose a suitable workup protocol for patients and assessing the efficacy of surgical procedures.

Material and methods: A prospective analysis of patients with anal fistulas undergoing fistulotomy, fistulectomy, ligation of fistula tract (LIFT), seton placement from November 2017 to November 2018 was conducted.

Results: Hundred patients with newly diagnosed fistulae from Nov2017-18 were included. Longest follow-up time was 10 months, minimum follow-up was 6months. Mean follow-up time was 9months. The group consisted of 76 male and 24 female patients. Age group 21- 40 and $41-60$ is having maximum number of patients 40 each respectively. Thirty six patients are having complex fistulae and 64 are having simple fistulae. Twenty eight patients had anterior external opening and 72 had posterior external opening.

Conclusions: Fistula- in-ano is a common and painful anorectal problem in the society. It is common in young and middle aged persons with more incidences in males than females. Exact etiology is still unknown but factors like constipation, low fiber diet and less physical activities play an important role. Sixty four patients out 100 who underwent proper fistulotomy and fistulectomy had no recurrences despite 30 patients having co morbidities.

Keywords: Management of Fistula, Fistula in ANO

\section{INTRODUCTION}

Fistula in ano is a persistent epitheliazed tract developing between the anal canal and the perianal skin. Most commonly due to an infection in the anal crypts and can occur after abscess drainage. Crohn's disease, trauma, radiation, or malignancy can also cause fistulae. Simple fistulae can be broadly classified into intersphincteric and low transsphincteric. Complex fistulae include high transsphincteric, suprasphincteric, extrasphincteric, multiple tracts, horseshoe tracts, recurrent fistulae. Anterior fistulae in women can be associated with Crohn's disease, radiation therapy, or malignancy. ${ }^{2}$ The surgical management of anal fistula should be to resolve sepsis, promote healing of the tract and preserving the sphincters for continence. Fistulotomy and fistulectomy are very effective for simple and most distal fistula, with $100 \%$ success. ${ }^{3}$ As of today there is no single best technique proposed for complex fistulae. The management of complex fistulae still remains a challenge and studies on recurrence and follow up are limited. ${ }^{4}$ Rojanasakul et $\mathrm{al}^{5}$ proposed the ligation of the intersphincteric fistula tract (LIFT) procedure, sphincter-preserving surgery, for the management of complex anal fistulas in 2007. The above authors postulated that the ligation and excision of the intersphincteric portion of the fistula tract without disturbing the sphincter would obliterate the internal opening, as well as eliminate the septic focus and thus fecal incontinence is almost negligible.

The aim of this article was to provide an overview about the presentation, age, sex distribution, predisposing factors for the development of fistula-in-ano and to propose a suitable workup protocol for patients suffering from fistulain-ano and also assessing the efficacy and safety of surgical procedures.

\section{MATERIAL AND METHODS}

Our study underwent Institutional ethical board approval. A prospective analysis of patients with anal fistulas undergoing surgical treatment from November 2017 -18 was conducted. Written and informed consent for the procedure and agreement to participate in regular follow-up assessments were obtained for all included patients.

Inclusion criteria were all crypto glandular anal fistulas in patients with newly diagnosed anal fistulae. 
All patients were referred for MRI scans to rule out subsidiary tracts and other complications.

In Exclusion criteria, patients who presented with recurrent fistulae, suspected or confirmed Crohn's disease, Tuberculosis, previous radiation therapy and colorectal malignancy are excluded.

A confidential database was created to collect information regarding all patients in the present series. Variables considered were age, gender, co-morbidities, type of fistula, intra- and postoperative complications, duration of followup (minimum 6 months).

\section{Surgical Technique}

All patients underwent standard Clinical colorectal examination and radiological investigations. Patients received no bowel preparation or enemas prior to surgery. Antibiotics were given $1 \mathrm{~h}$ before surgery. Surgery was performed under spinal anesthesia, in lihtotomy position. The fistulous tract and internal opening was identified carefully using a malleable probe and the tract was injected with hydrogen peroxide for clear visualization of the tract and its potential branches.

Procedures done were fistulotomy, fistulectomy, ligation of fistula tract (LIFT), seton placement.

\section{Postoperative care}

All procedures were performed as inpatients. Post procedure they were instructed to use sitz baths four times daily and always after passing stool. They were discharged with prescription of antibiotics, analgesics, stool softeners along with an instruction to have high fiber diet and plenty oral fluids. Patients were routinely reviewed in the outpatient clinic two weeks after surgery. Subsequent clinical follow-up was scheduled at 2-to 4-week intervals until clinical diagnosis of healing. For patients with suspected recurrence, MRI was done to confirm. All included patients were clinically reevaluated in order to rule out recurrence and to determine the follow-up duration.

Fistula recurrence at any point in time in the postoperative follow-up was defined by clinical examination, and MRI (magnetic resonance imaging). Data was analyzed using SPSS .21 version and results were obtained.

\section{RESULTS}

Data was collected from November 2017-18 for 100 patients with newly diagnosed fistulae in ano. Longest follow-up time was 10 months, minimum follow-up was 6months. The group consisted of 76 male and 24 female patients. Simple fistulae were 64 and complex fistulae were 36 with 9 being high transsphinteric, 64 being low transsphincteric and 27 being interspincteric. Seventy patients had history of perianal abscess, 25 had fissure in ano and 5 patients had multiple opening with recurrences. Out of five, three are

\begin{tabular}{|c|c|c|c|c|c|c|c|}
\hline & & & Fistulectomy & Fistulotomy & Lift & Seton & \\
\hline \multirow[t]{8}{*}{ Age Category } & \multirow[t]{2}{*}{$<20$ years } & $\mathrm{n}$ & 1 & 1 & 0 & 0 & 2 \\
\hline & & $\%$ & $3.1 \%$ & $3.1 \%$ & $0.0 \%$ & $0.0 \%$ & $2.0 \%$ \\
\hline & \multirow[t]{2}{*}{$21-40$ years } & $\mathrm{n}$ & 7 & 13 & 17 & 3 & 40 \\
\hline & & $\%$ & $21.9 \%$ & $40.6 \%$ & $63.0 \%$ & $33.3 \%$ & $40.0 \%$ \\
\hline & \multirow[t]{2}{*}{$41-60$ years } & $\mathrm{n}$ & 15 & 9 & 10 & 6 & 40 \\
\hline & & $\%$ & $46.9 \%$ & $28.1 \%$ & $37.0 \%$ & $66.7 \%$ & $40.0 \%$ \\
\hline & \multirow[t]{2}{*}{$61-80$ years } & $\mathrm{n}$ & 9 & 9 & 0 & 0 & 18 \\
\hline & & $\%$ & $28.1 \%$ & $28.1 \%$ & $0.0 \%$ & $0.0 \%$ & $18.0 \%$ \\
\hline \multirow{2}{*}{\multicolumn{2}{|c|}{ Total }} & $\mathrm{n}$ & 32 & 32 & 27 & 9 & 100 \\
\hline & & $\%$ & $100.0 \%$ & $100.0 \%$ & $100.0 \%$ & $100.0 \%$ & $100.0 \%$ \\
\hline
\end{tabular}

\begin{tabular}{|c|c|c|c|c|c|c|c|}
\hline & & & \multicolumn{4}{|c|}{ Procedure done } & \multirow[t]{2}{*}{ Total } \\
\hline & & & Fistulectomy & fistulotomy & lift & seton & \\
\hline \multirow[t]{10}{*}{ Healing Rate (in weeks) } & \multirow[t]{2}{*}{ 6-9 Weeks } & $\mathrm{n}$ & 0 & 28 & 22 & 1 & 51 \\
\hline & & $\%$ & $0.0 \%$ & $87.5 \%$ & $81.5 \%$ & $11.1 \%$ & $51.0 \%$ \\
\hline & \multirow[t]{2}{*}{$10-13$ weeks } & $\mathrm{n}$ & 32 & 4 & 0 & 0 & 36 \\
\hline & & $\%$ & $100.0 \%$ & $12.5 \%$ & $0.0 \%$ & $0.0 \%$ & $36.0 \%$ \\
\hline & \multirow[t]{2}{*}{ 14-20 weeks } & $\mathrm{n}$ & 0 & 0 & 1 & 4 & 5 \\
\hline & & $\%$ & $0.0 \%$ & $0.0 \%$ & $3.7 \%$ & $44.4 \%$ & $5.0 \%$ \\
\hline & \multirow[t]{2}{*}{ 20-24 weeks } & $\mathrm{n}$ & 0 & 0 & 0 & 3 & 3 \\
\hline & & $\%$ & $0.0 \%$ & $0.0 \%$ & $0.0 \%$ & $33.3 \%$ & $3.0 \%$ \\
\hline & \multirow[t]{2}{*}{ still following up } & $\mathrm{n}$ & 0 & 0 & 4 & 1 & 5 \\
\hline & & $\%$ & $0.0 \%$ & $0.0 \%$ & $14.8 \%$ & $11.1 \%$ & $5.0 \%$ \\
\hline \multirow{2}{*}{\multicolumn{2}{|c|}{ Total }} & $\mathrm{n}$ & 32 & 32 & 27 & 9 & 100 \\
\hline & & $\%$ & $100.0 \%$ & $100.0 \%$ & $100.0 \%$ & $100.0 \%$ & $100.0 \%$ \\
\hline \multicolumn{8}{|c|}{ Note: $P$ value $<0.001$ is significant } \\
\hline \multicolumn{8}{|c|}{ Table-2: Healing rates with type of procedure } \\
\hline
\end{tabular}




\begin{tabular}{|c|c|c|c|c|c|}
\hline & & & \multicolumn{2}{|c|}{ DM } & \multirow[t]{2}{*}{ Total } \\
\hline & & & No & Yes & \\
\hline \multirow[t]{10}{*}{ Healing Rate (in weeks) } & \multirow[t]{2}{*}{ 6-9 Weeks } & $\mathrm{N}$ & 42 & 9 & 51 \\
\hline & & $\%$ & $52.5 \%$ & $45.0 \%$ & $51.0 \%$ \\
\hline & \multirow[t]{2}{*}{ 10-13 weeks } & $\mathrm{N}$ & 25 & 11 & 36 \\
\hline & & $\%$ & $31.3 \%$ & $55.0 \%$ & $36.0 \%$ \\
\hline & \multirow[t]{2}{*}{ 14-20 weeks } & $\mathrm{N}$ & 5 & 0 & 5 \\
\hline & & $\%$ & $6.3 \%$ & $0.0 \%$ & $5.0 \%$ \\
\hline & \multirow[t]{2}{*}{ 20-24 weeks } & $\mathrm{N}$ & 3 & 0 & 3 \\
\hline & & $\%$ & $3.8 \%$ & $0.0 \%$ & $3.0 \%$ \\
\hline & \multirow[t]{2}{*}{ still following up } & $\mathrm{N}$ & 5 & 0 & 5 \\
\hline & & $\%$ & $6.3 \%$ & $0.0 \%$ & $5.0 \%$ \\
\hline \multirow{2}{*}{\multicolumn{2}{|c|}{ Total }} & $\mathrm{N}$ & 80 & 20 & 100 \\
\hline & & $\%$ & $100.0 \%$ & $100.0 \%$ & $100.0 \%$ \\
\hline
\end{tabular}

\begin{tabular}{|c|c|c|c|c|c|}
\hline & & & \multicolumn{2}{|c|}{ CAD } & \multirow[t]{2}{*}{ Total } \\
\hline & & & No & yes & \\
\hline \multirow[t]{10}{*}{ Healing Rate (in weeks) } & \multirow[t]{2}{*}{ 6-9 Weeks } & $\mathrm{N}$ & 46 & 5 & 51 \\
\hline & & $\%$ & $51.7 \%$ & $45.5 \%$ & $51.0 \%$ \\
\hline & \multirow[t]{2}{*}{ 10-13 weeks } & $\mathrm{N}$ & 30 & 6 & 36 \\
\hline & & $\%$ & $33.7 \%$ & $54.5 \%$ & $36.0 \%$ \\
\hline & \multirow[t]{2}{*}{ 14-20 weeks } & $\mathrm{N}$ & 5 & 0 & 5 \\
\hline & & $\%$ & $5.6 \%$ & $0.0 \%$ & $5.0 \%$ \\
\hline & \multirow[t]{2}{*}{ 20-24 weeks } & $\mathrm{N}$ & 3 & 0 & 3 \\
\hline & & $\%$ & $3.4 \%$ & $0.0 \%$ & $3.0 \%$ \\
\hline & \multirow[t]{2}{*}{ still following up } & $\mathrm{N}$ & 5 & 0 & 5 \\
\hline & & $\%$ & $5.6 \%$ & $0.0 \%$ & $5.0 \%$ \\
\hline \multirow{2}{*}{\multicolumn{2}{|c|}{ Total }} & $\mathrm{N}$ & 89 & 11 & 100 \\
\hline & & $\%$ & $100.0 \%$ & $100.0 \%$ & $100.0 \%$ \\
\hline
\end{tabular}

\begin{tabular}{|c|c|c|c|c|c|}
\hline & & & \multicolumn{2}{|c|}{ CRF } & \multirow[t]{2}{*}{ Total } \\
\hline & & & no & yes & \\
\hline \multirow[t]{10}{*}{ Healing Rate (in weeks) } & \multirow[t]{2}{*}{ 6-9 Weeks } & $\mathrm{N}$ & 46 & 5 & 51 \\
\hline & & $\%$ & $51.1 \%$ & $50.0 \%$ & $51.0 \%$ \\
\hline & \multirow[t]{2}{*}{ 10-13 weeks } & $\mathrm{N}$ & 31 & 5 & 36 \\
\hline & & $\%$ & $34.4 \%$ & $50.0 \%$ & $36.0 \%$ \\
\hline & \multirow[t]{2}{*}{ 14-20 weeks } & $\mathrm{N}$ & 5 & 0 & 5 \\
\hline & & $\%$ & $5.6 \%$ & $0.0 \%$ & $5.0 \%$ \\
\hline & \multirow[t]{2}{*}{ 20-24 weeks } & $\mathrm{N}$ & 3 & 0 & 3 \\
\hline & & $\%$ & $3.3 \%$ & $0.0 \%$ & $3.0 \%$ \\
\hline & \multirow[t]{2}{*}{ still following up } & $\mathrm{N}$ & 5 & 0 & 5 \\
\hline & & $\%$ & $5.6 \%$ & $0.0 \%$ & $5.0 \%$ \\
\hline \multirow{2}{*}{\multicolumn{2}{|c|}{ Total }} & $\mathrm{N}$ & 90 & 10 & 100 \\
\hline & & $\%$ & $100.0 \%$ & $100.0 \%$ & $100.0 \%$ \\
\hline
\end{tabular}

having crohn's disease and were referred to another center for management.

Total 32 ( 6 female, 26 male) patients underwent fistulectomy, $32(6$ female, 26 male) patients underwent fistulotomy, 27 (9 female and 18 male) patients underwent ligation of fistula tract (lift) and 9(3 female and 6 male) patients underwent seton surgery. Healing time 6-9 weeks (51patients), 10-13 weeks (36 patients), 14-20 weeks (5 patients), 20-24 weeks ( 3 patients) and 5 patients are still being followed and Table 3 shows details about healing time with type of procedure. 


\begin{tabular}{|c|c|c|c|c|c|}
\hline & & & \multicolumn{2}{|c|}{ DM } & \multirow[t]{2}{*}{ Total } \\
\hline & & & no & yes & \\
\hline \multirow[t]{4}{*}{ recurrences } & \multirow[t]{2}{*}{ no } & $\mathrm{N}$ & 75 & 20 & 95 \\
\hline & & $\%$ & $93.8 \%$ & $100.0 \%$ & $95.0 \%$ \\
\hline & \multirow[t]{2}{*}{ yes } & $\mathrm{N}$ & 5 & 0 & 5 \\
\hline & & $\%$ & $6.3 \%$ & $0.0 \%$ & $5.0 \%$ \\
\hline \multirow{2}{*}{\multicolumn{2}{|c|}{ Total }} & $\mathrm{N}$ & 80 & 20 & 100 \\
\hline & & $\%$ & $100.0 \%$ & $100.0 \%$ & $100.0 \%$ \\
\hline
\end{tabular}

Twenty patients had diabetes mellitus and healing time was shown in table 4.Coronary heart disease patients are 11 in number and their healing time was shown in table 5. Ten patients had chronic renal failure and their healing time showed in table 6.

\section{DISCUSSION}

Rojanasakul et al published the first paper concerning the LIFT technique in 2007 (using that name of the technique) and reported impressive healing rates (over 94\%) with no complications. ${ }^{6} \mathrm{~A}$ detailed description of the technique was published two years later by the same author. ${ }^{7}$ Since then there have been many papers published by several authors. Bleier et al reported less impressive healing rates (57\%) in 2010; however their group was more heterogeneous as it included patients who had failed surgical treatment at least once before. ${ }^{8}$ Wallin et al published in the same year reported even lower healing rates (40\%). ${ }^{9}$ Various other studies that followed, showed varying results, from very encouraging rates of $83-86 \% \%^{10,11,12}$ to $62-68 \%$, where groups were more heterogeneous. ${ }^{13-16}$ The authors reported that the results depend on whether the patient had previous surgeries. Therefore comparative studies started emerging. Abcarian et al clearly noted the difference in results of the procedure depending on past surgeries - overall healing rate reported was $74 \%$, but those operated for the first time had a healing rate of $90 \%$. In contrast, the patients with one previous surgery had a healing rate of $75 \%$, and the patients with two or more previous surgeries had a success rate of $65 \% .{ }^{14}$ Lehmann et al reported a healing rate of $65 \%$ in a study group consisting of patients who had two or more failed surgeries. ${ }^{17}$ Recent reviews gathered data from several publications to point the same correlation. ${ }^{15,18}$ VergaraFernandez et al analyzed 18 publications and concluded that LIFT procedure was the best procedure for patients with no prior surgery. ${ }^{15}$ Nevertheless, overall long term follow-up success rates reported so far vary from $62 \%$ to $73 \% \%^{19,20,21}$ Several authors modified the procedures with implantation of plugs, meshes, or using fibrin glue (Bio-LIFT, LIFT-Plug, LIFT-Plus), but there was not enough evidence that variants in the surgical technique achieve better results. ${ }^{15,22-25}$ There is some evidence that a two-step approach, preliminary seton drainage, prior to the LIFT procedure enhances the LIFT's healing rates ${ }^{13,26}$, but not all studies report using setons, so the results are hard to compare.

However, the ratio was 50:50 in several author reviews, this difference was due to variation in a geographical area. ${ }^{18}$
Shanwani et al's study revealed primary healing rate was $82 \%$, with a median healing time of 7 weeks (range, 4-10) with recurrence seen in 8 patients over a period of 3-8 months, with no significant morbidity. ${ }^{14}$

In our study, Patients who underwent fistulotomy and fistulectomy for simple fistulae healed completely in an average time of 13 weeks. Patients who underwent LIFT procedure had an average healing time of 16weeks. 4 patients who had recurrences were sent for colonoscopy and 3 patients proved to have crohn's. One patient underwent seton is still being followed up.

Presence of co morbidities like DM (euglycemic control), $\mathrm{CAD}$, and CRF in presence of our surgical expertise did not affect the healing time and recurrences as well.

\section{CONCULSION}

Fistula- in-ano is a common and painful anorectal problem in the society. All fistulae in ano should be thoroughly investigated with appropriate radiological modalities to classify the condition before embarking on a definitive procedure. In the present study we had a total of only 5 recurrences despite some patients having co morbidities like DM, CAD and CRF. This condition can be prevented with slight modification of lifestyle like preventing constipation by eating high fiber diet, drinking enough water, occasional use of a stool softener, careful anal hygiene after defecation and doing moderate intensity exercise

\section{REFERENCES}

1. Abcarian AM, Estrada JJ, Park J, et al. Ligation of intersphincteric fistula tract: early results of a pilot study. Dis Colon Rectum 2012; 55(7):778-82

2. Aboulian A, Kaji AH, Kumar RR. Early result of ligation of the intersphincteric fistula tract for fistulain-ano. Dis Colon Rectum 2011; 54(4):289-92

3. Westerterp M, Volkers NA, Poolman RW, van Tets WF. Anal fistulotomy between Skylla and Charybdis. Colorectal Dis. 2003;5(2):549-551

4. Campbell ML, Abboud EC, Dolberg ME, et al. Treatment of refractory perianal fistulas with ligation of the intersphincteric fistula tract: preliminary results. Am Surg 2013; 79(3):723-7

5. Christoforidis D, Etzioni DA, Goldberg SM, et al.Treatment of complex anal fistulas with the collagen fistula plug. Dis Colon Rectum 2008; 51(6):1482-7

6. Rojanasakul A, Pattanaarun J, Sahakitrungruang C, Tantiphlachiva K: Total anal sphincter saving technique for fistula-in-ano; the ligation of intersphincteric fistula 
tract. J Med Assoc Thail Chotmaihet Thangphaet Mar; 2007; 90(3): 581-86

7. Rojanasakul A: LIFT procedure: a simplified technique for fistula-in-ano. Tech Coloproctology 2009; 13(3): 237-40.

8. Bleier JIS, Moloo H, Goldberg SM: Ligation of the intersphincteric fistula tract: an effective new technique for complex fistulas. Dis Colon Rectum 2010; 53(1): 43-46.

9. Wallin UG, Mellgren AF, Madoff RD, Goldberg SM: Does ligation of the intersphincteric fistula tract raise the bar in fistula surgery? Dis Colon Rectum 2012; 55(11): 1173-78

10. Shanwani A, Nor AM, Amri N: Ligation of the intersphincteric fistula tract (LIFT): a sphinctersaving technique for fistula-in-ano. Dis Colon Rectum 2010; 53(1): 39-42

11. Sileri P, Franceschilli L, Angelucci GP et al.: Ligation of the intersphincteric fistula tract (LIFT) to treat anal fistula: early results from a prospective observational study. Tech Coloproctology 2011; 15(4): 413-16

12. Tan K-K, Tan IJ, Lim FS et al.: The anatomy of failures following the ligation of intersphincteric tract technique for anal fistula: a review of 93 patients over 4 years. Dis Colon Rectum 2011; 54(11): 1368-72.

13. Tan K-K, Alsuwaigh R, Tan AM et al.: To LIFT or to flap? Which surgery to perform following seton insertion for high anal fistula? Dis Colon Rectum 2012; 55(12): 1273-77.

14. Abcarian AM, Estrada JJ, Park J et al.: Ligation of intersphincteric fistula tract: early results of a pilot study. Dis Colon Rectum 2012; 55(7): 778-82.

15. Vergara-Fernandez O, Espino-Urbina LA: Ligation of intersphincteric fistula tract: What is the evidence in a review? World J Gastroenterol WJG 2013; 19(40): 6805-13.

16. Ooi K, Skinner I, Croxford M et al.: Managing fistulain-ano with ligation of the intersphincteric fistula tract procedure: the Western Hospital experience. Colorectal Dis Off J Assoc Coloproctology G B Irel 2012; 14(5): 599-603.

17. Lehmann J-P, Graf W: Efficacy of LIFT for recurrent anal fistula. Colorectal Dis Off J Assoc Coloproctology G B Irel 2013; 15(5): 592-95

18. Alasari S, Kim NK: Overview of anal fistula and systematic review of ligation of the intersphincteric fistula tract (LIFT).Tech Coloproctology 2014; 18(1): 13-33.

19. Liu WY, Aboulian A, Kaji AH, Kumar RR: Longterm results of ligation of intersphincteric fistula tract (LIFT) for fistula-in-ano. Dis Colon Rectum 2013; 56(3): 343-47.

20. Hong KD, Kang S, Kalaskar S, Wexner SD: Ligation of intersphincteric fistula tract (LIFT) to treat anal fistula: systematic review and metaanalysis. Tech Coloproctology 2014; 18(8): 685-91.

21. . Sileri P, Giarratano G, Franceschilli L et al.: Ligation of the Intersphincteric Fistula Tract (LIFT): A Minimally Invasive Procedure for Complex Anal Fistula: Two-Year Results of a Prospective Multicentric Study. Surg Innov 2013 Nov 6
22. Han JG, Yi BQ, Wang ZJ et al.: Ligation of the Intersphincteric Fistula Tract Plus Bioprosthetic Anal Fistula Plug (LIFT-Plug): a New Technique for Fistulain-Ano. Colorectal Dis Off J Assoc Coloproctology G B Irel 2012 Oct 16.

23. Ellis CN: Outcomes after repair of rectovaginal fistulas using bioprosthetics. Dis Colon Rectum 2008; 51(7): 1084-88.

24. Ellis CN: Outcomes with the use of bioprosthetic grafts to reinforce the ligation of the intersphincteric fistula tract (BioLIFT procedure) for the management of complex anal fistulas. Dis Colon Rectum 2010; 53(10): 1361-64.

25. Sirikurnpiboon S, Awapittaya B, Jivapaisarnpong P: Ligation of intersphincteric fistula tract and its modification: Results from treatment of complex fistula. World J Gastrointest Surg 2013; 5(4): 123-28

26. Mushaya C, Bartlett L, Schulze B, Ho Y-H: Ligation of intersphincteric fistula tract compared with advancement flap for complex anorectal fistulas requiring initial seton drainage. Am J Surg 2012; 204(3): 283-89.

\section{Source of Support: Nil; Conflict of Interest: None}

Submitted: 16-05-2019; Accepted: 02-06-2019; Published online: 15-07-2019 